\title{
Developing a model of participation post-stroke: a mixed-methods approach
}

\author{
Ruth Barclay-Goddard • Jacquie Ripat • \\ Nancy E. Mayo
}

Accepted: 21 June 2011/Published online: 12 July 2011

(C) The Author(s) 2011. This article is published with open access at Springerlink.com

\begin{abstract}
Purpose To develop and verify a model of participation post stroke, as a domain of health related quality of life.

Methods An explanatory sequential mixed-methods design was selected. The quantitative phase developed a participation model with data from an observational study of 453 participants at 12 months post-stroke, using structural equation modeling. The qualitative phase followed to verify the model from the perspective of individuals post-stroke. Data was collected from two groups of eight stroke survivors involved in a multicentre trial about participation in the community. Individuals took photographs to describe participation; discussion of photographs was conducted over the course of three focus groups, and analysis identified emergent categories related to the model.

Results The 12-month post stroke participation model consisted of latent variables: accomplishment, restricted
\end{abstract}

R. Barclay-Goddard ( $₫)$

Department of Physical Therapy, School of Medical

Rehabilitation, University of Manitoba, R106-771 McDermot

Ave, Winnipeg, MB R3E 0T6, Canada

e-mail: barclayg@cc.umanitoba.ca

J. Ripat

Department of Occupational Therapy, School of Medical

Rehabilitation, University of Manitoba, R106-771 McDermot

Ave, Winnipeg, MB R3E 0T6, Canada

N. E. Mayo

James McGill Professor, Department of Medicine, Division of Clinical Epidemiology, School of Physical and Occupational

Therapy, McGill University, Montreal, Canada

N. E. Mayo

Division of Geriatrics, Health Center Royal Victoria Hospital, McGill University, Site Ross Pavilion R4.29, 687 Pine Ave W, Montreal, QC H3A 1A1, Canada roles, and health efficacy. The model fit was reasonable: normed $\chi^{2}=2.95$, RMSEA $=0.066(0.052 ; 0.079)$. The qualitative data verified the model; participants initiated photo-taking and discussion of all aspects of the model. Concepts of social support, environment, and cognitive difficulties were also discussed in relation to participation. Conclusions The participation model was developed and verified. Additions to future models are suggested. Theoretical, clinical, and research implications are discussed.

Keywords Stroke $\cdot$ Participation $\cdot$ Health related quality of life - Mixed-methods · Photovoice .

Structural equation modeling

$\begin{array}{ll}\text { Abbreviations } \\ \chi^{2} & \text { Chi-square } \\ \text { EQ5D } & \text { EuroQol } \\ \text { FIML } & \text { Full information maximum likelihood } \\ \text { HRQL } & \text { Health-related quality of life } \\ \text { IADL } & \text { Instrumental activities of daily living } \\ \text { ICF } & \text { International Classification of Functioning, } \\ & \text { Disability and Health } \\ \text { PBSI } & \text { Preference Based Stroke Index } \\ \text { RMSEA } & \text { Root mean square error of approximation } \\ \text { SEM } & \text { Structural equation modeling } \\ \text { SF-36 } & \text { Short Form 36 } \\ \text { SIS } & \text { Stroke Impact Scale } \\ \text { VAS } & \text { Visual analogue scale }\end{array}$

\section{Introduction}

Enhancing health related quality of life (HRQL) is an overall goal in rehabilitation and should be important to rehabilitation theory, research, and practice [1]. The 
ultimate aim of rehabilitation post-stroke is to improve an individual's HRQL, with treatment focused on domains of HRQL important to the individual client with stroke [2]. It is therefore important to evaluate all aspects of stroke, which are reflected in HRQL domains, to be able to plan future services [2]. The three domains commonly used to describe HRQL include physical, psychological, and social functioning, with the concept of overall health/general well being also often included [3]. These three HRQL domains have been broadly conceptualized as physical function [4], mental health [5], and participation and have been modeled separately for an overall conceptualization of HRQL after stroke. A key area of interest is focusing on how health care professionals can improve the participation of individuals with disabilities [6-11].

The International Classification of Functioning, Disability and Health (ICF) defines participation as "involvement in a life situation", while participation restrictions are defined as "problems an individual may experience in involvement in life situations" [12]. Consistent with the tenets of the ICF, participation is identified in objective terms, and is viewed as the anticipated outcome of the rehabilitation process. Conversely, participation can be self-perceived. The self-perceived perspective explores feelings of inclusion, engagement, access, and reciprocity $[13,14]$ and addresses not only the activities that one engages in, but also engagement as "filtered through the person's experiences, values, and beliefs" [14].

Both objective and self-perceived perspectives acknowledge the importance of the environment in creating, or preventing, opportunities for participation. For example, the ICF is explicit in stating that the environment (e.g. technological, natural, physical, social, attitudinal, policy) will serve to interact with the individual to promote or restrict participation $[12,15]$. Participation includes actions and roles that an individual requires for one's well-being; these roles and activities vary from person to person depending on their values [16].

Post-stroke, participation restrictions are common [1719]. Engaging in meaningful activity during the day, doing household tasks, traveling, and activities of daily living are the most commonly occurring participation restrictions and activity limitations in community dwelling individuals post-stroke [2]. Factors that predict participation at both 6 months and 2-4 years post-rehabilitation include: age, comorbidity, affect and coordination of the lower extremity [17]. Depression, functional score and stroke recovery have also been suggested as predictors of participation [20].

The prominence of this construct in recent literature and discourse suggests that a comprehensive understanding of how participation is conceptualized and experienced poststroke would be an important addition to the fields of participation and HRQL research after stroke. A model describing participation values was developed qualitatively with people with disabilities, however, it is not specific to stroke [21]. By bringing together both objective and self-perceived perspectives, we will develop a thorough understanding of the meaning and experience of participation for individuals post-stroke [14, 22].

Purpose and objectives

The purpose of this explanatory sequential mixed-methods design [23] was to develop and verify a model of participation post-stroke. The objectives of this study were threefold:

1. Developing a model of participation post-stroke

2. Exploring self-perceived aspects of participation poststroke

3. Verifying the participation model using self-perceived participation data

\section{Methods}

Quantitative component: structural equation modeling (objective 1)

To address the first objective, secondary data analysis of the study "Understanding Quality of Life Post-Stroke: A Study of Individuals and their Caregivers" [24] was conducted. This study is a longitudinal observational study of 678 individuals at $1,3,6$, and 12 months post-stroke; 453 completed the 12 month evaluation. HRQL was measured in the original observational study with both generic and disease-specific indices: Short Form 36 [25], EuroQol [26], Health Utilities Index [27], Stroke Impact Scale [28], and the Preference Based Stroke Index [29]. Data screening and data preparation was completed with SAS 9.14 [30]; structural equation modeling (SEM) analysis utilized LISREL 8.72, SIMPLIS and PRELIS [31].

SEM was used to model constructs (latent variables) which are represented by various measured outcomes; in this case, subscales or items from various health indices used in the observational study [32]. A measurement model (which describes associations between variables) was developed to demonstrate associations between the latent variables of social function, role function, role restrictions, and health efficacy with the related measured variables.

We (RBG and NM) chose to model the 12-month time period after stroke, as it is a time at which participation may be a particular focus for stroke survivors who have returned to living in the community. The measurement model was based on theory and the literature, as described below. Content of the latent variables in the participation model were based in part on the Medical Outcomes Study Framework of Health Indicators description of social 
Table 1 Framework for the initial participation model

\begin{tabular}{lllll}
\hline HRQL index & \multicolumn{2}{l}{ Latent variables (participation constructs) } & & Health efficacy \\
\cline { 2 - 5 } & $\begin{array}{l}\text { Social function } \\
\text { (later combined as 'Accomplishments') }\end{array}$ & Restricted roles & Role physical & General health \\
\hline Short form 36 & Social function & - & Role emotional & VAS (visual analogue scale) \\
EuroQol & - & Usual activities & & - \\
Health utilities index & - & - & - & VAS-global recovery \\
Stroke impact scale & Social participation & - & - & - \\
Preference based stroke Index & Recreational activities & Driving & Work &
\end{tabular}

Each latent variable was associated with related items and subscales from HRQL indices that were available in the observational study

functioning: social function, role function, and role limitations due to emotional problems or to physical health [33]. A latent variable of self-perceived health and recovery (health efficacy) was also included. In previous work using SEM, leisure activities (an aspect of participation) have been associated with well-being (satisfaction) [19]. In older adults with stroke living in the community, a positive effect of activities of daily living and IADL on a general health rating and an assessment of change in health was demonstrated [34]. Table 1 shows a framework for the initial participation model that lists items from each HRQL index available in the observational study, identifying how they were associated with each latent variable in the initial participation model.

Once a model is developed, the fit of each model is assessed in numerous ways. The model chi-square $\left(\chi^{2}\right)$ is commonly reported in the SEM literature. As model $\chi^{2}$ increases, the fit of a model becomes worse; the $\chi^{2}$ tests the difference between the observed model and a model that has a perfect population fit [32]. A non-significant $\chi^{2}$ means that there is little difference between the models, suggesting a good fit. Models with large sample sizes, however, can often be rejected because the model $\chi^{2}$ is affected by sample size [35]. It is therefore suggested that a variety of fit indices be used. Some researchers use a normed $\chi^{2}$ ( $\chi^{2} /$ degrees of freedom) as a way to decrease the effect of the sample size on the $\chi^{2}$; values up to 5.0 have been used to suggest a reasonable model fit [32]. The root mean square error of approximation (RMSEA) measures the lack of fit in a model compared to the population. A value of $\leq 0.05$ is considered a close fit, $0.05-0.08$ is a reasonable fit and $\geq 0.10$ a poor fit [36].

Full information maximum likelihood (FIML) was the estimation method used for SEM analysis, to account for missing data [37]. Not all questions were answered by each respondent. Only the fit indices described above were available with FIML in LISREL SIMPLIS. With FIML, missing data is not imputed; parameter estimates are estimated directly from the raw data with iterative computer algorithms [37]. The parameter estimates that are produced with FIML are considered to be unbiased under the assumption that the data is missing at random; FIML also assumes normality [37].

Qualitative component: photovoice and focus groups (objectives 2 and 3 )

Photovoice and focus groups were used to address selfperceived aspects of participation post-stroke. Photovoice is a participatory research method founded on "critical consciousness, feminist theory, and documentary photography", using community-based photography as a means of sharing lived experiences [38]. Using photovoice, participants can inform researchers of issues using self-selected photographic images. Focus groups were selected as they rely on the engagement and interaction of a peer group to explore thoughts and experiences of participation that related to their everyday life [39]. Participants were stroke survivors living in the community who were part of a multi-centre trial about participation post-stroke. Two groups of eight participants each contributed to this component; participant groups occurred several months apart.

Participants attended an information session on photovoice, and assessed for required camera adaptations to ensure use (e.g. one-handed access, larger buttons). Digital cameras were purchased for each participant, and adaptations made where required. Participants then engaged in a 2-h session where they were shown how to use the cameras, practiced taking photos, and discussed safety issues.

The following week, participants engaged in an initial focus group, where focus group members were asked to reflect on, and discuss, the meaning of participation. At this time, two models of participation were presented-the quantitatively developed Participation Model, as described above, and a model of participation developed by people with disabilities, as described by Hammel [21]. The models 


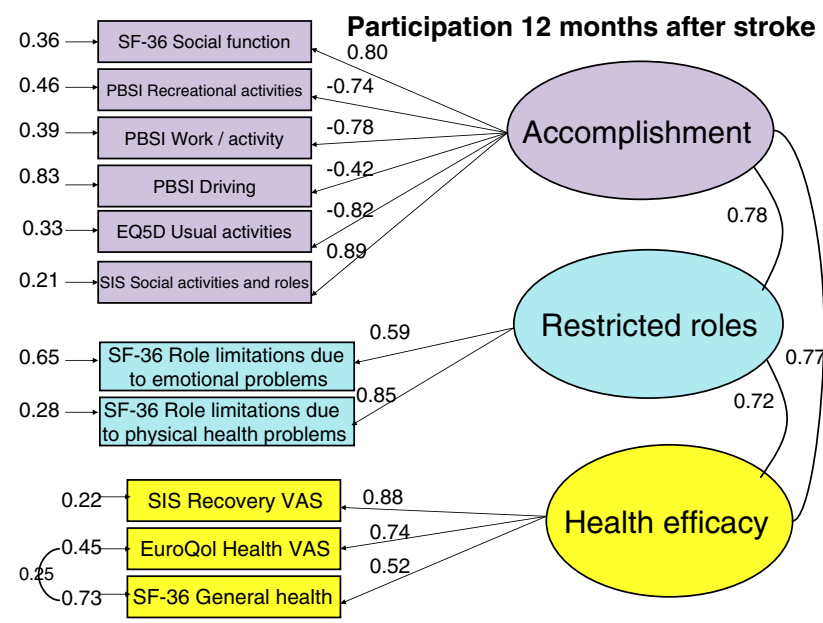

Fig. 1 Participation model -12 months. $\chi^{2}=118.13, \quad d f=40$, $P=0.0000$, normed $\chi^{2}=2.95$, RMSEA $=0.066(0.052 ; 0.079)$. Standardized model shown. Negative correlations reflect the measures PBSI and the EQ5D, where the highest score is the worse health condition. SF-36 Short Form 36, SIS Stroke Impact Scale, PBSI Preference Based Stroke Index, EQ5D EuroQol 5 dimensions

were used to initiate discussion, but neither model was focussed on at this time, so as to not overly influence discussions and photo taking. Over the next several weeks, participants took photos, with questions such as, "What does participation mean to you?; What does it mean to fully participate?; What helps you to participate?; and What makes it difficult to participate?" provided as cues for picture-taking.

Subsequently, participants worked with a research assistant to select up to five photos that best described their participation experiences. The selected photos were captioned with participant's associated descriptions and inserted into presentation software. This presentation was shared in the context of a second focus group to engage participants in wider discussion of the topic. Finally, a second cycle of picture-taking and a third focus group discussion ensued with each of the two groups. The Participation Model (Fig. 1) was shown again at the third focus group and participants were asked to comment specifically on the model, and whether they felt it represented participation after stroke, as they understood it. At each focus group, discussions were digitally recorded and later transcribed verbatim.

Interpretation of the photographic and transcribed data focused on the meanings, intentions, and relationship of photos to the construct of participation as discussed by the participants. Qualitative description, as described by Sandelowski, was the approach used in this aspect of the study [40, 41]: this method focuses on gaining a detailed description and understanding of a phenomenon, as perceived and shared by the participants. The transcripts were reviewed first individually and then collaboratively by RBG and JR, using an inductive process to identify emergent categories. Initial analysis consisted of a line-byline reading of each transcript, in order of collection, and underlining of key words and phrases [42]. Initial codes were assigned to represent relevant clusters of information: RBG and JR then met to compare coding. Coding discrepancies were discussed until agreement was reached; codes were organized into categories representing the most prominent and recurrent ideas and key quotes representing the categories were extracted. Data saturation was reached after analysis of the focus group transcripts $(n=6)$; i.e., redundancies in data were identified, with no new categories emerging by the sixth transcript.

To verify the model of participation post-stroke, we used a triangulation approach [43, 44]. We considered where categories between the quantitative and qualitative components converged or diverged [43, 44]. This stage of analysis was theory-driven, focusing on linking the emergent categories from the qualitative component to the model of participation that was developed with SEM. Categories that differed from the developed model were considered for possible addition to the model.

For both Objectives 2 and 3, trustworthiness was sought through the use of two primary researchers involved in data analysis, the use of two separate groups of stroke survivors, with each group participating in two rounds of picturetaking, and by using the participants' own words as supporting the development of the categories.

\section{Ethical considerations}

The University of Manitoba Health Research Ethics Board granted ethics approval for all components of the study. All participants in the qualitative component of the study provided informed consent and photo release prior to enrolment. Participants kept the cameras for personal use when the project was completed. In accordance with ethics procedures, pseudonyms were assigned to participants and any potentially identifying information was blurred in photographs to protect anonymity.

\section{Results}

Quantitative component: structural equation modeling (objective 1)

453 participants took part in the 12 month post-stroke evaluation. See Table 2 for a description of the study participants. Data screening suggested the missing data pattern was missing at random; all variables used were moderately non-normal. 
Table 2 Description of the study participants-quantitative and qualitative components

\begin{tabular}{|c|c|c|c|c|c|}
\hline $\begin{array}{l}\text { Gender } \\
\text { freq }(\%)\end{array}$ & $\begin{array}{l}\text { Age in years } \\
\text { mean (SD) [range] }\end{array}$ & $\begin{array}{l}\text { Side of lesion } \\
\text { freq }(\%)\end{array}$ & $\begin{array}{l}\text { Years post-stroke } \\
\text { mean (SD) }\end{array}$ & $\begin{array}{l}\text { Comfortable gait speed } \\
\mathrm{m} / \mathrm{s} \text { mean }(\mathrm{SD})\end{array}$ & Walking aids used \\
\hline \multicolumn{6}{|c|}{ Quantitative component $(n=453)$} \\
\hline Female: 211 (46.6) & Female: 68.5 (15.8) & Left 198 (43.7) & 1 year post-stroke evaluation & NA & NA \\
\hline \multirow[t]{3}{*}{ Male: 242 (53.4) } & Male: 65.6 (13.5) & Right 218 (48.1) & & & \\
\hline & All: 66.9 (14.7) & Bilateral 22 (4.9) & & & \\
\hline & {$[26-97]$} & Other $15(3.3)$ & & & \\
\hline \multicolumn{6}{|c|}{ Qualitative component $(n=16)$} \\
\hline Female: 4 (25.0) & Female: 64.3 (9.9) & Left 7 (43.7) & $3.8(3.0)$ & $0.8(0.4)^{\mathrm{a}}$ & $\begin{array}{l}\text { 6-cane, } 1 \text {-wheeled } \\
\text { walker, 9-none }\end{array}$ \\
\hline \multirow[t]{3}{*}{ Male: 12 (75.0) } & Male: 61.8 (7.5) & Right 8 (50.0) & & & \\
\hline & All: 62.4 (7.9) & Bilateral $1(6.3)$ & & & \\
\hline & [44-77] & & & & \\
\hline
\end{tabular}

NA not assessed

${ }^{\mathrm{a}}$ Normal gait speed for women aged $60-69=1.16 \mathrm{~m} / \mathrm{s}$, for men $=1.28 \mathrm{~m} / \mathrm{s}$ [50]

\section{The measurement model}

A model was developed with the four latent variables (social function, role function, restricted roles, and health efficacy) and the measured variables described in Table 1. Due to suggestions from the modification indices, an error correlation was added between general health perceptions of the SF-36 and the EuroQol visual analogue scale, as they measure related concepts. The correlation between the social function and role function latent variables was so high at 0.93 that they were likely measuring the same construct. The two latent variables were therefore combined into one latent variable, renamed 'accomplishment'. This led to a model with reasonable fit: $\chi^{2}=118.13, d f=40$, $P=0.0000$, normed $\chi^{2}=2.95$, RMSEA $=0.066(0.052$; $0.079)$. The $\mathrm{p}$ values for the $\chi^{2}$ do not suggest a good fit, however, having a significant $\chi^{2}$ is common with large sample sizes [32]. It is therefore important to look at other measures of fit as well [32]. The normed $\chi^{2}$ and RMSEA both suggest a reasonable fit. Figure 1 displays the participation model at 12 months.

Qualitative component: photovoice and focus groups (objectives 2 and 3)

\section{Objective 2}

Participants involved in the qualitative component of the study are described in Table 2. Participation, as described by the individuals in this study included both the experience and the activity. Many identified a social aspect to participation, for example Janet described participation as "to be included...to feel included". A sense of accomplishment and being active was also predominant, for instance, John stated that participation meant, "being able to be here (in the group) and do the things everybody else does". However, individuals in the study experienced participation in the context of involvement in self-selected activities, such as leisure activities, socializing with friends, or involvement in volunteer activities. Ian described it this way: “...for me I joined a football pool again this year. I have no real interest in it because I don't sit there and study the stats, the point spreads and that, I'm just going because I've been doing it for 15 years so I, everybody talks about how their teams are doing, I wanted to have mine too so. I guess I joined it for the social connection."

Activities that held meaning to the participants were individual and unique and reflected the values that they individually held. "Like you might want to participate this way, and I might want to participate my way, and it might be totally different ways" (Gary). In this way, participation did not refer to involvement in a prescribed set of activities, but rather people described how they engaged in activities that they found meaningful and enjoyable. At times, these activities were goal-oriented and purposeful, at other times they described a sense of simply passing time: "Say if you did crosswords or Sudoku and that takes away hours of your time. I mean that's how I spend my time... it keeps me active mentally" (Roger).

Overall, these participants conceptualized participation as the engagement in self-selected activities that served to promote a sense of inclusion, accomplishment, and as a means to stay mentally, physically, and socially active.

\section{Objective 3}

Participants took pictures that represented the construct "Accomplishment", with photos addressing each of the associated measured variables in the model. At times, 
photos represented accomplishment in a valued activity that they had found difficult to do after their stroke, such as Janet, who stated: "This is a one handed knitting holder. Someone in the group suggested I try it out so I would be able to knit. It's a good thing that I can use it." They derived meaning and satisfaction in resuming those activities that had been impacted by the stroke. For example, Andy who had aphasia following his stroke shared a picture of the place that he had recently begun volunteering. He talked about it as follows: "Go here once a week. It's exciting. Q: Why do you like it? Andy: It's something to do. Q: Do you feel [it is] meaningful doing it? Andy: Yes." Sometimes photos portrayed something participants felt had been accomplished, at other times the pictures represented the challenges they faced in accomplishing something. For many of the participants, the loss of ability to drive was very distressing, and regaining one's license was a major accomplishment and milestone. Norm described his photo in this way: "Panel truck. I've had it since 2000 ... Once I got my license, I got back on the road".

With the construct "Restricted Roles", participants talked about the roles that they felt restricted in performing, and how the physical and cognitive changes experienced affected them emotionally. For example, Don showed the picture in Fig. 2a, stating: "There's those stupid shoes. The other ones are too hard to put on and take off. When you've taught grade one you don't want to be wearing Velcro shoes." Similarly, Amed discussed how his role in the family and community had been affected: "I find that I've lost my, the, the respect and dignity that I used to have within my own family structure because of this particular stroke problem...so because of that I, I've lost quite a bit of my stature and um now I'm just being treated like as if I'm a necessary evil". Sometimes, participants gave up roles and important activities, as Sam explained of his picture: "Walking is difficult and I was trying to use this to represent the problems...I used to walk up and down the block all the time with my wife. But it's just too hard now. I'm too slow."

Participants addressed the construct of "Health Efficacy" in terms of their sense of recovery, and acceptance of limitations, from stroke. For example, Richard stated: "Well after I had my stroke, it was about 2 month after I went back to the [gym]. I couldn't hardly do anything. And now gradually I built myself up a bit and so, will I ever recover 100\% I don't know. But I've accepted it, I've made it 1 day at a time." Participants discussed how they perceived their general health and how they needed to address a Restricted Roles

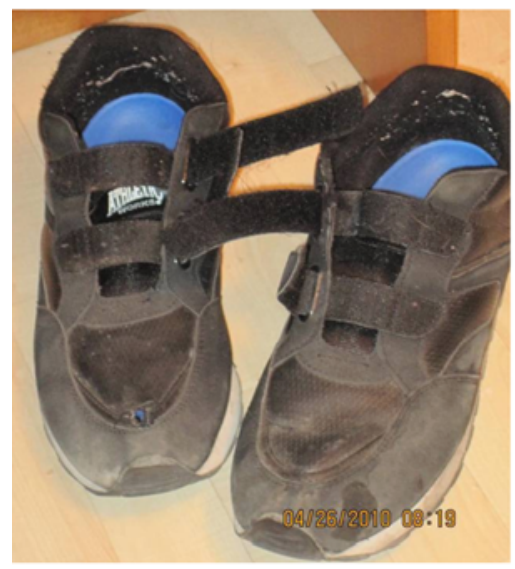

c Accomplishments and Health Efficacy

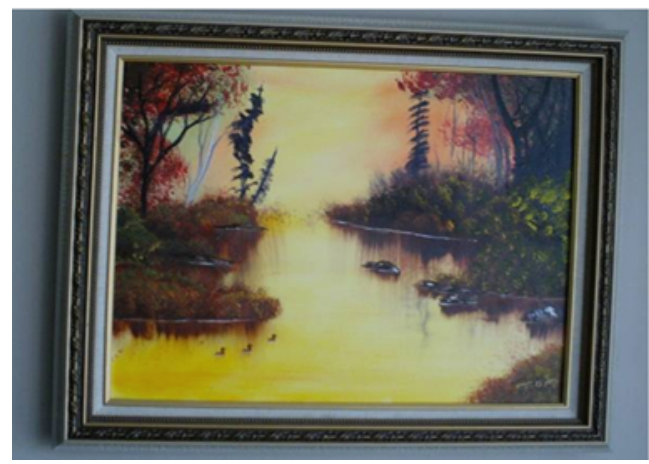

b Accomplishments and Restricted Roles

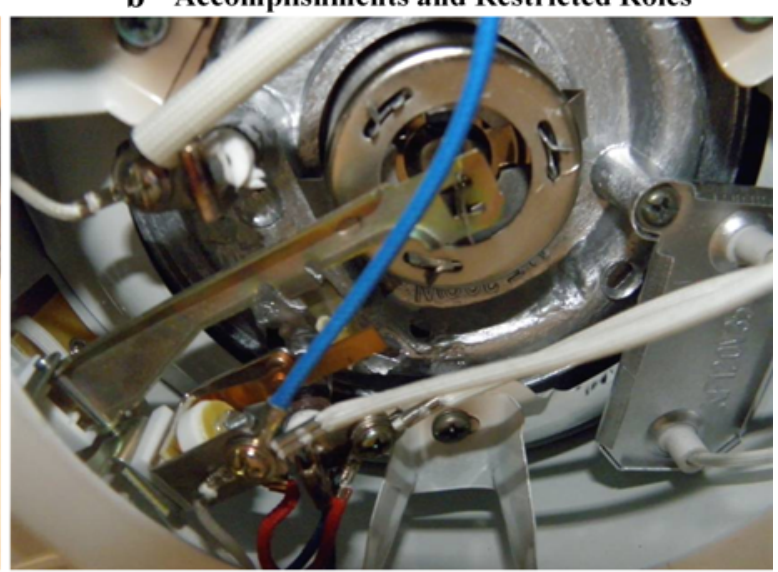

d Health Efficacy and Restricted Roles

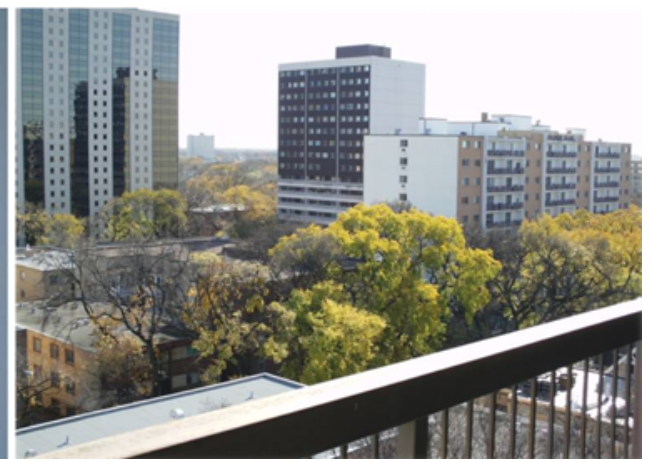

Fig. 2 Representative photos 
the issues that they now faced, such as pain. Don captioned his photo of various medications: "Pain killers. It's just constant, how much you take. It's trying not to taking it. There is endless cautions to not taking. It helps, but how much can you afford to take."

The associations between the constructs (latent variables) in the participation model also became apparent through discussion. These associations are represented in the model in Fig. 1 by the curved lines between latent variables. Correspondingly, participants depicted the link between accomplishment and restricted roles using photos of how they addressed role limitations in order to accomplish necessary tasks, often using adaptive equipment or strategies. Ken, who experienced cognitive impairments post-stroke used photography as a cognitive aid, stating: "Fixing the kettle. Taking pictures so I know how to put it back together" (Fig. 2b). Participants connected accomplishment and health efficacy using photos that represented how performing an activity that they perceived as difficult to do post-stroke promoted their sense of health-efficacy. Benjamin shared the photo in Fig. 2c, and captioned it: "My first work of art since my stroke. I felt I was able to do something". Finally, the link between restricted roles and health efficacy was also discussed and photographed by participants. Photos and associated descriptions coded in this way connected the concept of perceived recovery with the limitations experienced from stroke. Simon shared a set of photos he had taken, one showing his apartment's interior and the second of the view from his apartment (Fig. 2d), stating: "This is my nice safe haven inside the house, but, the pictures of outside, that's the world I have to get back into".

Although not part of the participation model in Fig. 1, the environment was identified as playing an important role in their life and community participation. Photos included pictures of their environmental supports and relationships; this included peers, family, friends, and pets, and participants emphasized the crucial role that their social network provided for them. Daniel summed it up in this way: "Family's everything to me. That's what I like to do. I want to spend as much time as I can with my family." Participants placed lower emphasis on barriers and supports in the physical environment, although challenging walking conditions were identified, as shown in the picture taken by Andy: "Q: You walk on the street because it is more smooth on the sidewalk? Andy: Yes. Bump, bump, bump, bump [Pointing to orthotic]".

At the final focus group, when the Participation Model (Fig. 1) was shown, one participant specifically identified that the model captured participation and provided an example of a train trip that he had taken. For him, an example of accomplishment was being able to go on a long train trip with his wife. Restricted roles encompassed the challenges that he perceived in walking on a moving train, and health efficacy referred to his perception of recovery since the stroke. As he described, at first, he was unsure if he could climb onto the top berth in the train, but he had actually been able to, for him, reflecting his perception of recovery.

\section{Discussion}

Overall, the qualitative component verified the quantitatively developed model of participation. Participants verified model components and linkages with some additions, and used personal lived experiences, photos, and stories to describe how components were linked to their perception of participation. The participants, through discussion and/ or photos, addressed each of the latent variables of accomplishments, restricted roles, and health efficacy as well as associations between the latent variables. Participants also self-initiated discussion and photography of each measured variable. However, there were a few concepts discussed that were not present in the quantitatively derived model. These included the limitations to participation due to cognitive function, the importance of social support and maintaining relationships, and aspects of the physical environment that hindered participation. Subsequently, through the mixed-methods analysis, researcher interpretation of focus group data verified the quantitatively-derived Participation Model.

A proposed model for future consideration is seen in Fig. 3. It is a simplified version of the model in Fig. 1 with the addition of support and relationships and the physical environment as all encompassing aspects that affect

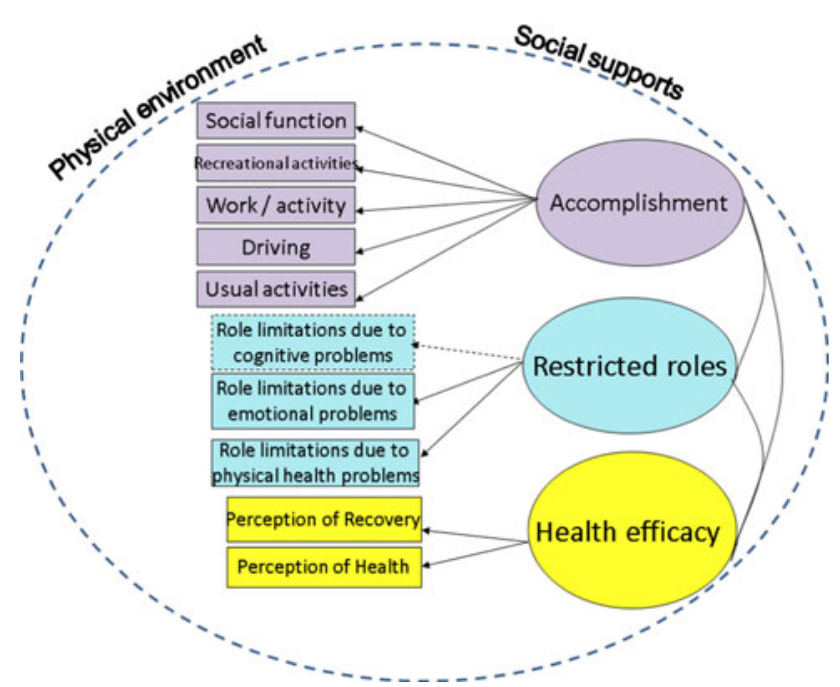

Fig. 3 Participation model—suggested additions based on qualitative component. Dotted lines represent additions to the model 
participation, as well as adding the concept of role limitations due to cognitive problems.

A recent study demonstrated that participation is decreased in those individuals with cognitive deficits after stroke compared to those without cognitive deficits poststroke, but that participation did increase over a period of 6 months after discharge from hospital [45]. In a study that examined barriers to participation post-stroke, individuals described cognitive issues and physical issues the most, as well as psychological and social barriers [14].

Social support and its relationship to participation have been explored in the literature. In a qualitative study of participation in leisure activities after a stroke, one of four themes that emerged was that of "gratitude for help and support", describing support of "family, friends, neighbours or community support services" [46]. Another study concluded that "subjective support was found to moderate the effect of functional limitation on participation" [47].

Environmental barriers were part of the discussion in the focus groups, however, we were surprised that the physical environment didn't figure more prominently as a barrier to participation, as had been found in another study of participation post-stroke [14]. Perhaps participants felt that they were regaining function and therefore needed to accommodate to the environment, rather than vice versa; the participants in the qualitative component were part of a trial that included some aspects that could be considered rehabilitative in nature which may have influenced this perspective. There are five chapters of environmental factors in the ICF $[12,15]$. Two of these are "natural environment and human made changes to environment" (physical environment) and "supports and relationships" [12], both of which were apparent in the focus group discussions. A study exploring how the environment influences participation in elderly people, of whom half had a stroke, found that barriers in the physical environment were not an significant issue; the social environment (help from people, such as social support from family and friends) was highly important in influencing participation [48].

\section{Theoretical implications}

This unique mixed-methods approach to quantitatively modeling and qualitatively verifying a model of participation after stroke leads to further theoretical implications. With the initial SEM model of participation after stroke, the social function and role function latent variables were highly correlated, suggesting that they are measuring the same concept, leading to combining the two concepts into one latent variable, named 'accomplishment'. This leads to the question-are social function and role function so conceptually similar that they are really one concept?
The role of social support and relationships in facilitating participation came out consistently in the discussions with the participants. This aspect needs to be considered in future models of participation after stroke as well as other health conditions. With the new knowledge of participation after stroke brought by both the SEM modeling and qualitative verification with individuals with stroke, a revised definition of participation after stroke could be attempted.

\section{Clinical implications}

Social support and relationships should be addressed as an important aspect of participation when evaluating and discussing participation with clients after stroke. The participation model may be used as a guide to the selection of the types of concepts which could be measured clinically, when wanting to measure participation. For example, evaluating aspects of accomplishments, restricted roles, and health efficacy, as well as the physical environment and support and relationships.

\section{Research implications}

Combining the objective and self-perceived perspectives provided a more inclusive view of participation after stroke than could have been achieved by using only a single approach. This type of mixed-methods approach could be used more frequently in the future to explain and verify a quantitatively developed model with qualitative data. The use of photography in describing theory and models provided a richness and depth to the focus group discussions. The process of self-selection of photos and captions required thoughtful reflection by participants, allowing them to share personal feelings, ideas, and perceptions of their participation experiences in a way that could not have been achieved through other means. Evaluating whether the additions to the model add to the construct of participation after stroke should be undertaken. Verification of this model in other health conditions would also be beneficial to the field. In future studies evaluating participation after stroke, the participation model can be used as a guide for the types of outcomes that could be measured.

\section{Limitations}

For the quantitative component, measured variables were chosen for the Participation Model that had been collected in the original study [24]. This determined the variables in the model to some degree. However, the conceptualization of the model was based on the literature. We used a process of theory-driven analysis to verify the model, which may be viewed as constraining the inductive nature of qualitative analysis. However, additional concepts emerged from 
analysis and thus the research was not constrained by the pre-existing model. Participants in the qualitative component were not all at 12 months post-stroke, as opposed to the participants in the quantitative component. All were, however, community dwelling individuals, contributing to the transferability [49] of the study results.

\section{Conclusions}

Participation is one domain of HRQL. A model of participation post-stroke was developed using SEM; it included the constructs of accomplishment, restricted roles, and health efficacy. This model was verified by photography and focus groups of individuals post-stroke. However, additions to future models may more fully explain participation after stroke. The participation model can be used theoretically for developing future models and defining participation; clinically to describe participation after stroke and provide a guide for evaluation of components of participation; and in research to evaluate future models in stroke and other health conditions, and guide measurement of outcome in participation research. These on-going efforts are essential as rehabilitation professionals continue to expand their focus beyond addressing the functional limitations of stroke, towards understanding how people are able to participate in their families, communities, and lives post-stroke.

Acknowledgments The Canadian Stroke Network funded the "Understanding Quality of Life Post-Stroke: A Study of Individuals and their Caregivers" observational study, the "Getting on with the Rest of your Life after Stroke" multi-centre trial, and the photovoice component of this study. We would like to thank Chris Urban, Kathie Beech-Nelson, the Stroke Recovery Association of Manitoba, and the participants.

Open Access This article is distributed under the terms of the Creative Commons Attribution Noncommercial License which permits any noncommercial use, distribution, and reproduction in any medium, provided the original author(s) and source are credited.

\section{References}

1. Renwick, R., \& Friefeld, S. (1996). Quality of life and rehabilitation. In R. Renwick, I. Brown, \& M. Nagler (Eds.), Quality of life in health promotion and rehabilitation (pp. 26-37). Thousand Oaks: SAGE Publications.

2. Mayo, N., Wood-Dauphinee, S., Cote, R., Durcan, L., \& Carlton, J. (2002). Activity, participation, and quality of life 6 months poststroke. Archives of Physical Medicine and Rehabiltation, 83, 1035-1042.

3. Sprangers, M. A. (2002). Quality-of-life assessment in oncology. Achievements and challenges. Acta oncologica Stockholm, Sweden, 41, 229-237.
4. Barclay-Goddard, R., Mayo, N., Lix, L., Tate, R., \& Weinberg, L. (2008). Does response shift occur in physical function post stroke? In Proceedings of Canadian Physiotherapy Association Congress.

5. Barclay-Goddard, R., Lix, L., Tate, R., Weinberg, L., \& Mayo, N. (2009). Response shift was identified over multiple occasions with a structural equation modeling framework. Journal of Clinical Epidemiology, 62, 1181-1188.

6. Cardol, M., De Jong, B. A., \& Ward, C. D. (2002). On autonomy and participation in rehabilitation. Disability and Rehabilitation, 24, 970-974.

7. Chan, S. C., \& Chan, A. P. (2007). User satisfaction, community participation and quality of life among Chinese wheelchair users with spinal cord injury: A preliminary study. Occupational Therapy International, 14, 123-143.

8. Coster, W., \& Khetani, M. A. (2008). Measuring participation of children with disabilities: Issues and challenges. Disability and Rehabilitation, 30, 639-648.

9. Gray, D. B., Hollingsworth, H. H., Stark, S. L., \& Morgan, K. A. (2006). Participation survey/mobility: Psychometric properties of a measure of participation for people with mobility impairments and limitations. Archives of Physical Medicine and Rehabilitation, 87, 189-197.

10. Noreau, L., Fougeyrollas, P., Post, M., \& Asano, M. (2005). Participation after spinal cord injury: The evolution of conceptualization and measurement. Journal of Neurologic Physical Therapy, 29, 147-156.

11. Perenboom, R. J. M., \& Chorus, A. M. J. (2003). Measuring participation according to the International Classification of Functioning Disability and Health (ICF). Disability and Rehabilitation, 25, 577-587.

12. World Health Organization. (2001). International classification of functioning, disability and health. Geneva: World Health Organization.

13. Brown, M. (2010). Participation: The insider's perspective. Archives of Physical Medicine and Rehabilitation, 91, S34-S37.

14. Hammel, J., Jones, R., Gossett, A., \& Morgan, E. (2006). Examining barriers and supports to community living and participation after a stroke from a participatory action research approach. Topics in Stroke Rehabilitation, 13, 43-58.

15. Schneidert, M., Hurst, R., Miller, J., \& Ustun, B. (2003). The role of environment in the international classification of functioning, disability and health (ICF). Disability and Rehabilitation, 25, 588-595.

16. Rochette, A., Korner-Bitensky, N., \& Levasseur, M. (2006). 'Optimal' participation: A reflective look. Disability and Rehabilitation, 28, 1231-1235.

17. Desrosiers, J., Noreau, L., Rochette, A., Bourbonnais, D., Bravo, G., \& Bourget, A. (2006). Predictors of long-term participation after stroke. Disability and Rehabilitation, 28, 221-230.

18. Rochette, A., Desrosiers, J., \& Noreau, L. (2001). Association between personal and environmental factors and the occurrence of handicap situations following a stroke. Disability and Rehabilitation, 23, 559-569.

19. Sveen, U., Thommessen, B., Bautz-Holter, E., Wyller, T., \& Laake, K. (2004). Well-being and Instrumental Activities of Daily Living After Stroke. Clinical Rehabilitation, 18, 267-274.

20. Baseman, S., Fisher, K., Ward, L., \& Bhattacharya, A. (2010). The relationship of physical function to social integration after stroke. Journal of Neuroscience Nursing, 42, 237-244.

21. Hammel, J., Magasi, S., Heinemann, A., Whiteneck, G., Bogner, J., \& Rodriguez, E. (2008). What does participation mean? An insider perspective from people with disabilities. Disability and Rehabilitation, 30, 1445-1460.

22. Dijkers, M. (2010). Issues in the conceptualization and measurement of participation: An overview. Archives of Physical Medicine and Rehabilitation, 91, S5-S16. 
23. Creswell, J., \& Plano Clark, V. L. (2007). Designing and conducting mixed methods research. Thousand Oaks: SAGE Publications.

24. Wood-Dauphinee, S. (2003). Quality of life post stroke. Brainwaves-Newsletter for members of the Canadian Stroke Network.

25. Anderson, C., Laubscher, S., \& Burns, R. (1996). Validation of the short form (SF-36) health survey questionnare among stroke patients. Stroke, 27, 1812-1816.

26. Dorman, P., Waddell, F., Slattery, J., Dennis, M., \& Sandercock, P. (1997). Is the EuoQol a valid measure of health-related quality of life after stroke? Stroke, 28, 1876-1882.

27. Mathias, S., Bates, M., Pasta, D., Cisternas, M., Feeny, D., \& Patrick, D. (1997). Use of the health utilities index with stroke patients and their caregivers. Stroke, 28, 1888-1894.

28. Duncan, P., Wallace, D., Lai, S., Johnson, D., Embretson, S., \& Laster, L. (1999). The stroke impact scale version 2.0. Stroke, 30, 2131-2140.

29. Poissant, L., Mayo, N., Wood-Dauphinee, S., \& Clarke, A. (2003). The development and preliminary validation of a preference-based stroke index (PBSI). Health and Quality of Life Outcomes, 1.

30. SAS Institute. (2004). SAS/STAT user's guide, version 9. Cary, NC: SAS Institute, Inc.

31. Jöreskog, K., \& Sörbom, D. (1993). LISREL 8: Structural equation modeling with the SIMPLIS command language. Lincolnwood, IL: Scientific Software International Inc.

32. Kline, R. (2005). Principles and practice of structural equation modeling (2nd ed.). New York: The Guilford Press.

33. Stewart, A. (1992). The medical outcomes study framework of health indicators. In A. Stewart \& J. Ware (Eds.), Measuring functioning and well-being (pp. 12-24). Durham: Duke University Press.

34. Han, B., Small, B., \& Haley, W. (2001). The structure of selfrated health among community-dwelling older adults with stroke. Home Health Care Services Quarterly, 20, 1-15.

35. Hays, R., Revicki, D., \& Coyne, K. (2005). Application of structural equation modeling to health outcomes research. Evaluation and the Health Professions, 28, 295-309.

36. Browne, M., \& Cudeck, R. (1993). Alternative ways of assessing model fit. In K. Bollen \& J. Long (Eds.), Testing structural equation models (pp. 136-162). London: Sage Publications.

37. Enders, C. (2006). Analyzing structural equation models with missing data. In G. Hancock \& R. Mueller (Eds.), Structural equation modeling-A second course (pp. 313-342). Greenwich: Information Age Publishing.

38. Wang, C., \& Cameron, R. (1997). Photovoice: Concept, methodology, and use for participatory needs assessment. Health Education and Behaviour, 24, 369-387.

39. Hesse-Biber, S., \& Leavy, P. (2011). The practice of qualitative research (2nd ed.). Los Angeles: SAGE Publications.

40. Sandelowski, M. (2000). Whatever happened to qualitative description? Research in Nursing and Health, 23, 334-340.

41. Sandelowski, M. (2010). What's in a name? Qualitative description revisited. Research in Nursing and Health, 33, 77-84.

42. Miles, M., \& Huberman, A. (1994). An expanded sourcebook: Qualitative data analysis (2nd ed.). Thousand Oaks, California: SAGE Publications.

43. Farmer, T., Robinson, K., Elliott, S., \& Eyles, J. (2006). Developing and implementing a triangluation protocol for qualitative health research. Qualitative Health Research, 16, 377-394.

44. O'Cathain, A., Murphy, E., \& Nicholl, J. (2010). Three techniques for integrating data in mixed methods studies. BMJ, 341, $1147-1150$

45. Viscogliosi, C., Belleville, S., Desrosiers, J., Caron, C., \& Ska, B. (2010). Participation after a stroke: Changes over time as a function of cognitive deficits. Archives of Gerentology and Geriatrics (in press).

46. O'Sullivan, C., \& Chard, G. (2010). An exploration of participation in leisure activities post-stroke. Australian Journal of Occupational Therapy, 57, 159-166.

47. Beckley, M. N. (2006). Community participation following cerebrovascular accident: Impact of the buffering model of social support. The American Journal of Occupational Therapy, 60, $129-135$

48. Vik, K., Lilja, M., \& Nygård, L. (2007). The influence of the environment on participation subsequent to rehabilitation as experienced by elderly people in Norway. Scandinavian Journal of Occupational Therapy, 14, 86-95.

49. Law, M., \& MacDermid, J. (2008). Evidence-based rehabilitation: A guide to practice (2nd ed.). Thorfare, NJ: SLACK Incorporated.

50. Öberg, T., Karsznia, A., \& Öberg, K. (1993). Basic gait parameters: Reference data for normal subjects. Journal of Rehabilitation Research and Development, 30, 210-223. 